\title{
ESTRUTURA DE GOVERNANÇA CORPORATIVA DE UM HOSPITAL FILANTRÓPICO: UM ESTUDO DE CASO
}

\author{
J. M. ZANATTA ${ }^{1 *}$, J. K. D. V. TREVISAN ${ }^{2}$ e D. K. BAGGIO ${ }^{3}$ \\ 1,2,3 Universidade Regional do Noroeste do Estado do Rio Grande do Sul (UNIJUI) \\ josk85@hotmail.com*
}

Submetido 27/09/2016 - Aceito 16/01/2018

DOI: $10.15628 /$ holos.2018.5122

\section{RESUMO}

A governança corporativa é uma temática atual e de grande relevância para as organizações. Tem como norteador o manual de boas práticas de governança corporativa do Instituto Brasileiro de Governança Corporativa (IBGC). O presente estudo tem o objetivo de avaliar a estrutura de governança corporativo de um hospital filantrópico. Para tanto utilizou-se como caminho metodológico uma pesquisa teórica, qualitativo-descritiva, estudo de caso e entrevista semiestruturada. Conclui-se com a pesquisa que a Rede a qual o hospital pertence está organizada em estância canônica, institucional e empreendimento, e segue o manual de boas práticas de governança corporativa, no entanto, a unidade hospitalar apenas operacionaliza as diretrizes organizacionais.

PALAVRAS-CHAVE: Governança corporativa, Gestão hospitalar, Hospital filantrópico.

\section{CORPORATE GOVERNANCE STRUCTURE OF A HOSPITAL PHILANTHROPIC: A CASE STUDY}

\begin{abstract}
Corporate governance is a current topic of great relevance for organizations. It is guide by corporate governance manual of good practices of the Instituto Brasileiro de Governança Corporativa (IBGC). This study aims to assess the corporate governance structure of a philanthropic hospital. Therefore it was used as a methodological way a theoretical research, qualitative-
\end{abstract}




\section{INTRODUÇÃO}

A governança corporativa é uma temática atual e relevante, e tem ganho destaque na gestão das organizações. As últimas décadas foram marcadas por muitas transformações e inovações administrativas, tendo como marco principal a popularização da governança corporativa, que vem a contribuir para um sistema decisório equilibrado e que preserva os interesses dos stakeholders (VILELA;FERRAZ;FERRAZ, 2015). O termo stakeholders é definido como "grupo ou indivíduo que pode afetar ou é afetado pelo alcance dos propósitos de uma organização" (FREEMAN, 1984, p. 46).

As boas práticas de governança corporativa tiveram bons resultados nas empresas de capital aberto, o que atraiu o interesse de outras empresas que não dependem diretamente de investidores, mas que não podem ter descompassos entre proprietários e gestores (FONTES;VENTURA;MARUCCI, 2007). Neste sentido, o Instituto Brasileiro de Governança Corporativa passou a adotar o termo "organizações" ao invés de "organizações empresariais", para desta forma, abranger todas as naturezas jurídicas (IBGC, 2009).

No Brasil, existem três tipos principais de organizações hospitalares, classificadas de acordo com sua propriedade, denominadas de hospitais com fins lucrativos, hospitais filantrópicos e sem fins lucrativos, e hospitais públicos (MINISTÉRIO DA SAÚDE, 2001). Uma instituição hospitalar caracteriza-se como uma complexa organização social de difícil gestão e desenvolvimento e implementação de estratégias (KAPLAN; NORTON, 2000; PORCIUNCULA; SAUSEN, 2009; SILVA, 2013).

A profissionalização da gestão em instituições hospitalares tem sido objeto de estudo e discussões, a partir de diferentes práticas de administração, com o enfoque em conceitos como gestão baseada em evidência, aprendizagem organizacional e gestão do conhecimento (BORBA;NETO, 2008).

Este estudo tem o objetivo de avaliar a estrutura de governança corporativa de um hospital filantrópico, com característica de hospital geral, localizado na região Noroeste do Estado do Rio Grande do Sul. Para tanto, foi utilizado como norteador o manual de boas práticas de governança corporativa (IBGC, 2009), o qual contempla: propriedade, conselho de administração, gestão, auditoria independente, conselho fiscal, conduta e conflitos de interesses.

A organização objeto de estudo é integrante de uma rede, mantida por religiosas, com presença no Estado do Rio Grande do Sul, onde realiza trabalhos na área da saúde, educação e assistência social. Na área da saúde possui três hospitais, com características distintas, que contemplam oftalmologia, reabilitação física e hospital geral; na área da educação, conta com cinco colégios, de formação integral; e, na assistência social, possui três centros de formação, vinculados as políticas de assistência social.

A pesquisa foi realizada em um dos hospitais que compõe a rede, com características de hospital geral, filantrópico, com mais de 79 anos de atuação. Este hospital possui sólida vivência em programas de qualidade e tem buscado fomentar o trabalho em rede, como forma de alavancar a instituição e buscar vantagem competitiva. 
O organograma da rede está dividido em três partes: Instância Canônica, Instância Institucional e Instância Empreendimento. Na primeira, está demonstrada a estrutura hierárquica que contempla a vida religiosa, na segunda, esclarece a sua mantenedora enquanto rede, onde é apresentado a estrutura de governança e a sede, na terceira parte, é demonstrado a organização de cada unidade de negócio, com as estruturas da área da saúde, educação e assistência social. Para fins de melhor compreensão, o organograma será apresentado de forma desmembrada.

Para tanto, o trabalho está estruturado da seguinte forma: inicialmente é apresentada uma breve introdução ao trabalho, em seguida o referencial teórico que contempla a temática da gestão hospitalar e governança corporativa; em seguida, a metodologia utilizada; logo após a discussão do estudo de caso; e, por fim, as considerações finais.

\section{REFERENCIAL TEÓRICO}

No referencial teórico foram aprofundadas as temáticas de gestão hospitalar e governança corporativa, com o objetivo de compreender o contexto de hospital filantrópico e a estrutura de governança corporativa, para então, fundamentar a realização do estudo de caso.

\subsection{Gestão Hospitalar}

O termo Hospital pode ser definido e interpretado de várias formas. É uma organização complexa (MIRSHAWKA, 1994), que incorpora os avanços constantes do conhecimento e tecnologia médica (GONÇALVES, 1983). Para Daft (1999), o hospital é uma empresa de serviços, que pode ser classificada por cinco dimensões, conforme ilustrado no Quadro 1.

Quadro 1: Dimensões de um hospital. Fonte: Daft (1999).

Produção e consumo simultâneos: Esta dimensão é identificada nos atendimentos realizados pelos médicos e demais profissionais de saúde. $O$ atendimento é caracterizado como serviço e é entregue ao cliente ao mesmo tempo em que é realizado pelo profissional de saúde.

Produtos personalizados: Embora na medicina existam protocolos clínicos e condutas que devem ser seguidos, cada paciente é tratado como único e recebe atendimento personalizado.

Participação dos clientes no processo de produção: A consulta às informações do paciente é importante para o diagnóstico do médico.

Produto intangível: $\mathrm{O}$ produto é o atendimento.

Ênfase em pessoas: Os serviços só são realizados quando existe demanda, ou seja, deve existir cliente para a realização dos serviços. 
No Brasil, de acordo com a Confederação Nacional de Saúde - CNES (2016) existem seis mil setecentos e um hospitais, sendo que destes, $70 \%$ são privados. Esta informação é relevante, à medida em que o governo necessita desta rede de prestadores para garantir o pleno acesso à saúde aos usuários do Sistema Único de Saúde.

As instituições filantrópicas possuem um sistema tributário diferenciado, no entanto em contrapartida tem de seguir regras especificas e disponibilizar $60 \%$ de seus atendimentos para 0 Sistema Único de Saúde. Conforme a Lei 9.532, em seu artigo 15, é garantido a isenção de Imposto de Renda às instituições de caráter filantrópico, recreativo, cultural e científico e as associações civis que prestem os serviços para os quais houverem sido instituídas e os coloquem à disposição do grupo de pessoas a que se destinam, sem fins lucrativos.

\subsection{Governança corporativa}

O conceito de Governança Corporativa surgiu em 1932, nos Estados Unidos, com a publicação do livro "A Moderna sociedade anônima e a propriedade privada", que abordava a separação entre propriedade e gestão (SANTOS, 2004). Já no Brasil, a palavra Governança Corporativa emergiu da tradução literal da palavra inglesa "corporate governance" que significa um sistema pelo qual os acionistas administram a sua empresa e tratam de seus interesses (ANDRADE;ROSSETTI, 2004).

O conceito contemporâneo de Governança Corporativa teve início com os estudos de Jensen e Meckling (1976), que incluíram no assunto fragmentos da Teoria da Agência, onde se estabeleceu uma "relação de agência". Nesta relação de agência, os proprietários, definem um agente para desempenhar as atividades, onde existe delegação de poder e recompensa para as tomadas de decisões do agente.

Os pressupostos da teoria da agência formam um arcabouço teórico para se entender as relações contratuais atribuídas às organizações filantrópicas: Governo, doadores, população e voluntários e outros (Rezende, Facune e Dalmácio, 2009).

Na Figura 1, de um lado está o governo (forma de isenções tributárias, incentivos financeiros) e os doadores (pessoas físicas e jurídicas), que disponibilizam recursos para os hospitais filantrópicos. Do outro lado os voluntários (doam seu tempo e conhecimento como forma de auxilio em projetos) e a população (são beneficiários dos serviços prestados pelos hospitais). 


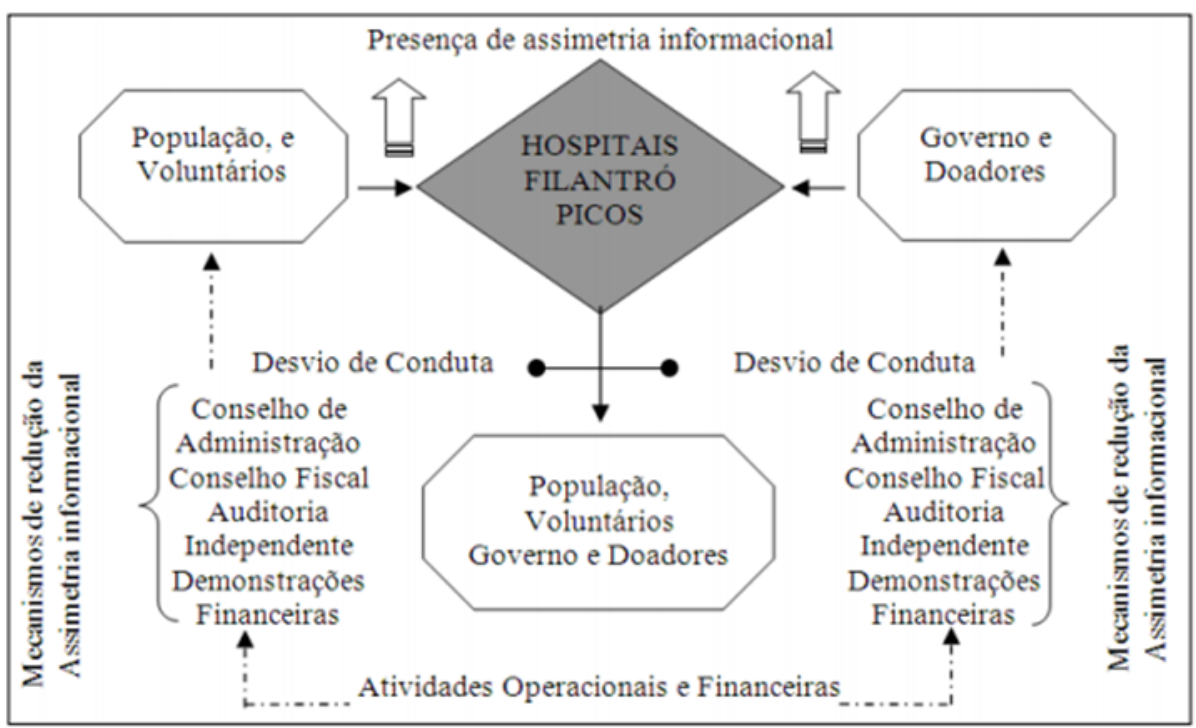

Figura 1: Teoria de agência nos hospitais filantrópicos. Fonte: Adaptado de Rezende, Facune e Dalmácio (2009, p.4).

Para assegurar um bom desempenho dos hospitais filantrópicos e aumentar seus propósitos, a governança corporativa possui dois objetivos essenciais: promover uma estrutura eficiente de incentivos para a administração objetivando a maximização de valor da empresa; e estabelecer responsabilidades e outros tipos de proteção para evitar que os acionistas majoritários, membros da diretoria e gestores façam qualquer tipo de expropriação de valor em detrimento dos acionistas minoritários e credores (CERDA, 2000).

Através destes, o primeiro objetivo busca o alcance do negócio, já no que diz respeito ao segundo objetivo, à distribuição dos resultados da empresa entre acionistas, gestores, credores. 0 objetivo principal dos hospitais filantrópicos é a geração de benefícios à sociedade em geral, com promoção da manutenção da saúde, o controle de epidemias e a participação nas estratégias governamentais em beneficio, mantendo-se o equilíbrio econômico financeiro da instituição.

O IBGC (2009, p. 19) complementa que "Governança Corporativa é o sistema pelo qual as organizações são dirigidas, monitoradas e incentivadas, envolvendo os relacionamentos entre proprietários, conselho de administração, diretoria e órgãos de controle". As boas práticas de governança corporativa são recomendações objetivas que buscam o alinhamento de interesses com o objetivo de contribuir para o acesso a recursos e a longevidade das organizações (IBGC, 2009).

Em destaque o IBGC (2009) apresenta os quatro princípios básicos da governança corporativa, importantes para criar a confiabilidade no ambiente interno, externo e de terceiros. Transparência: referente à obrigação de informar, de disponibilizar as informações que sejam do interesse das partes interessadas, e não apenas as obrigadas por lei ou regulamentos. Equidade: alude ao tratamento justo para com todos os sócios e partes interessadas. Prestação de contas: os agentes de governança devem prestar conta de sua atuação, assumindo as consequências de seus atos. Responsabilidade Corporativa: refere-se ao zelo pela sustentabilidade das organizações por parte dos agentes de governança. 
Para que as empresas adotem ações e práticas recomendadas para uma boa governança, é necessário que as mesmas possuam estruturas que facilitam o acontecimento destas práticas. Segundo o IBGC (2013), o conselho de administração, a auditoria independente e o conselho fiscal são instrumentos fundamentais para o exercício da governança corporativa, que podem ser observadas no Quadro 2.

Quadro 2: Conceitos de estrutura de governança corporativa. Fonte: Adaptado de Código das melhores práticas de governança corporativa $(2007,2009)$; Lodi (2000) e Paula (2000).

\begin{tabular}{|c|c|}
\hline Órgãos de Governança Corporativa & Descrição \\
\hline Conselho Fiscal & $\begin{array}{l}\text { O Conselho Fiscal é um órgão fiscalizador } \\
\text { independente da diretoria e do conselho de } \\
\text { administração, que busca, por meio dos } \\
\text { princípios de transparência, equidade e } \\
\text { prestação de contas, contribuir para o } \\
\text { melhor desempenho da organização. }\end{array}$ \\
\hline Conselho de Administração & $\begin{array}{l}\text { O Conselho de Administração deve zelar } \\
\text { pela observância dos valores, crenças e } \\
\text { propósitos dos acionistas, nas atividades da } \\
\text { empresa. Ainda, o artigo da Lei das } \\
\text { Sociedades por Açães determina a } \\
\text { competência do Conselho de } \\
\text { Administração. Deve-se destacar a } \\
\text { determinação de estratégias, a eleição e } \\
\text { destituição de diretores, a fiscalização da } \\
\text { gestão dos diretores e a eleição e } \\
\text { destinação dos auditores independentes. }\end{array}$ \\
\hline Auditoria Interna & $\begin{array}{l}\text { A auditoria interna tem como objetivo: } \\
\text { assessorar a administração, por meio de } \\
\text { exame de adequação e eficácia dos } \\
\text { controles internos da entidade; da } \\
\text { verificação da integridade e confiabilidade } \\
\text { dos sistemas; da constatação da } \\
\text { observância das políticas, metas, planos, } \\
\text { procedimentos, leis, normas e } \\
\text { regulamentos; da garantia da eficiência, } \\
\text { eficácia e economicidade do desempenho e } \\
\text { da utilização dos recursos. }\end{array}$ \\
\hline Auditoria Independente & $\begin{array}{l}\text { A auditoria independente pode ser } \\
\text { entendida como um órgão externo à } \\
\text { organização e isento de conflito de } \\
\text { interesses, que tem a atribuição básica de } \\
\text { verificar se as demonstrações financeiras } \\
\text { refletem adequadamente a realidade da }\end{array}$ \\
\hline
\end{tabular}




\begin{tabular}{|l|l|}
\hline Propriedade & organização. \\
\hline Gestão & $\begin{array}{l}\text { Cada sócio é um proprietário da } \\
\text { organização, na proporção de sua } \\
\text { participação no capital social. Com } \\
\text { assembleia geral e/ou reunião dos sócios. }\end{array}$ \\
\hline $\begin{array}{l}\text { diretor-presidente é responsável pela } \\
\text { gestão da organização e coordenação da } \\
\text { diretoria, atua como elo entre a diretoria e } \\
\text { o conselho de administração. É o } \\
\text { responsável ainda pela execução das } \\
\text { diretrizes fixadas pelo conselho de } \\
\text { administração e deve prestar constas a este } \\
\text { órgão, seu dever de lealdade é para com a } \\
\text { organização. }\end{array}$ \\
\hline
\end{tabular}

\section{PROCEDIMENTOS METODOLÓGICOS}

O presente trabalho consiste em uma pesquisa teórica, articulando conceitos e sistematizando a produção de uma área de conhecimento, de abordagem qualitativo-descritiva (GIL, 2002;VERGARA,2009), na qual os dados foram adquiridos por meio do contato pessoal com o gestor responsável pela área do estudo. Nesta pesquisa, foram considerados artigos, relatos e documentos relacionados com a temática governança corporativa, tendo como objetivo avaliar a estrutura de governança corporativa de um hospital filantrópico. Caracteriza-se como um estudo de caso único, uma investigação profunda de um fenômeno dentro de seu contexto, o que não permite generalização para o universo (YIN, 2001).

A unidade de análise da pesquisa foi um hospital filantrópico, com característica de hospital geral, localizado na região Noroeste do Estado do Rio Grande do Sul, pertencente a uma Rede que possui atuação na área da saúde, educação e assistência social. Adotou-se o procedimento de entrevista pessoal, utilizando-se de um roteiro semi-estruturado para a coleta de dados, onde cada questão estava relacionada com o Manual de Boas Práticas de Governança Corporativa (IBGC, 2009).

\section{RESULTADOS E DISCUSSÃO}

Para o estudo, o foco de análise foi a instância institucional e empreendimento, sendo que, a instância canônica foi apenas descrita para descrever os organogramas de forma completa, visto que, a vida religiosa tem grande importância para a Rede e é a base para suas ações. Nos organogramas da Rede, fica evidenciado a participação de religiosas e não religiosas na estrutura hierárquica, o que é uma singularidade da instituição estudada. 


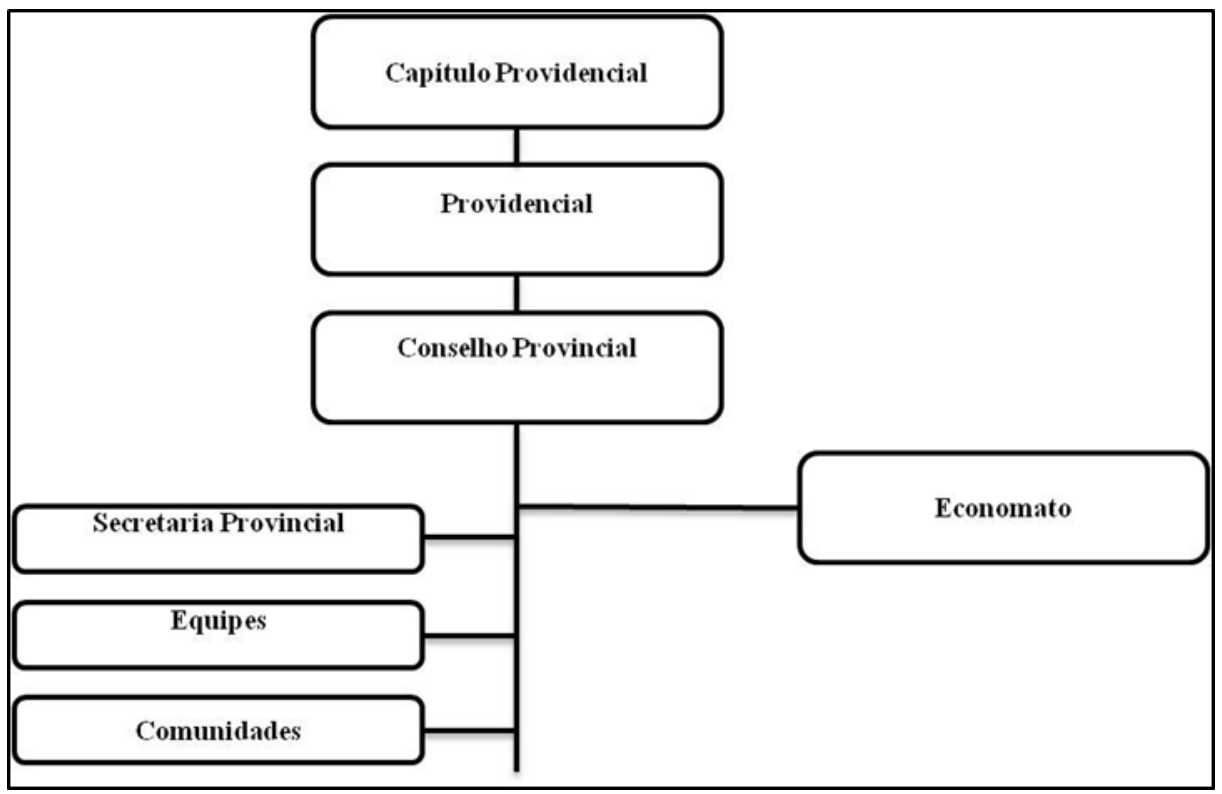

Figura 2: Organograma instância canônica

A organização objeto do estudo tem como sócias religiosas, que na esfera empresarial adotam denominação jurídica, em forma de associação. O conselho de administração da Rede é composto por sete pessoas, sendo, duas sócias, a presidente da associação, diretora financeira, diretora administrativa e dois conselheiros independentes. Todos os participantes do conselho de administração são religiosas, exceto os conselheiros independentes, os quais são contratados e possuem expertise nas áreas de educação e saúde. Conforme o IBGC (2009), o conselho de administração é responsável pelo direcionamento estratégico da organização, e é recomendado que seja composto por no mínimo cinco e no máximo onze membros.

A rede possui o processo de auditoria externa, com empresa independente contratada, sem vínculos institucionais, com periodicidade anual. Da mesma forma, são realizadas auditorias internas duas vezes ao ano. Segundo o IBGC (2009), toda organização deve ter suas demonstrações financeiras analisadas por auditor externo independente.

No organograma da instância institucional, a Rede possui ainda, religiosas que atuam como Diretora Executiva, Diretora Financeira e Coordenadora de Humanização e Espiritualidade, que são responsáveis pela gestão operacional da Rede, nas áreas da saúde, educação e assistência social. A diretora Executiva é responsável pela gestão, que contempla os serviços administrativos e corporativos, enquanto a Diretora Financeira é responsável pelas finanças e compras, e por fim, a Coordenadora de Humanização e Espiritualidade, define as políticas e ações de humanização e espiritualidade que serão seguidas pela Rede. 


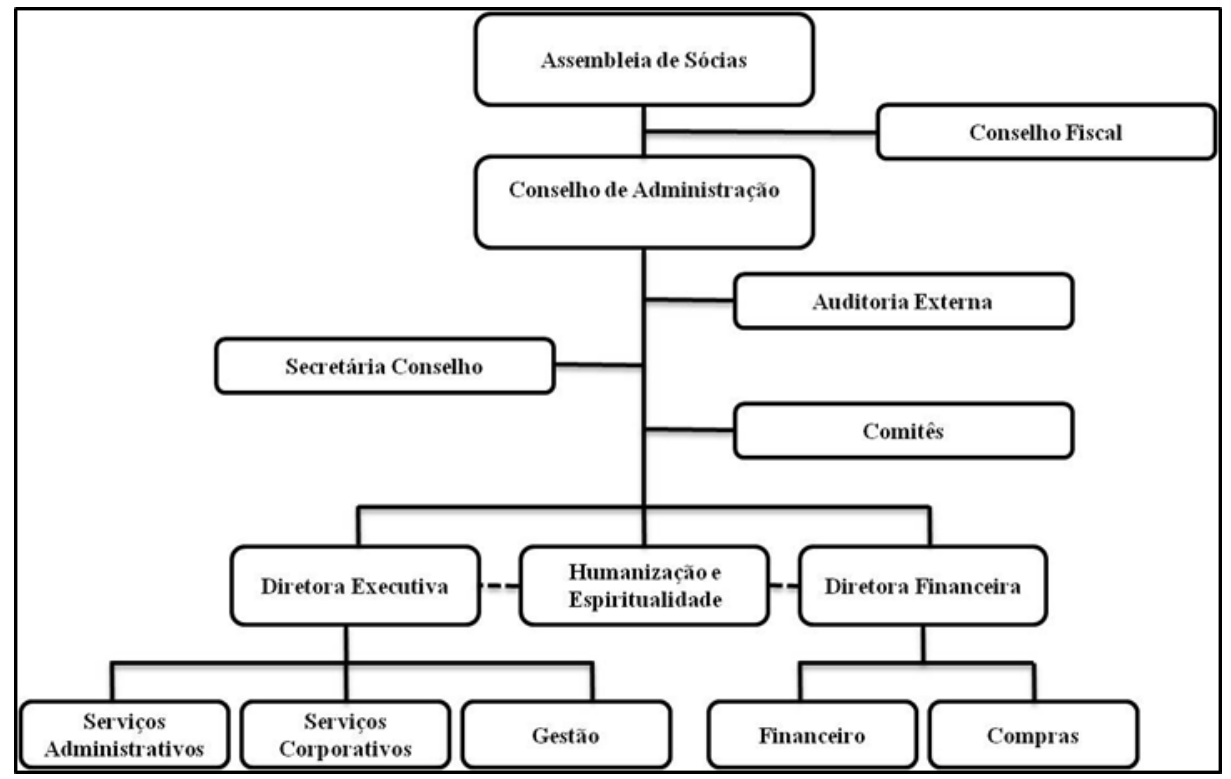

Figura 3: Organograma instância institucional

$\mathrm{Na}$ instância empreendimento, foi analisado a estrutura de governança de um dos hospitais pertencentes a Rede. A gestão é de responsabilidade da Diretora Geral, que é uma religiosa, designada pela Rede, para estar à frente desta unidade de negócio. Não existe prazo definido para o mandato, no entanto, existe um rodízio de religiosas, a fim de transferir conhecimentos para contribuir com a gestão de outras unidades da Rede.

A diretora Geral tem o auxílio de uma Diretora Financeira, um Diretor Executivo e uma Coordenadora de Humanização e Espiritualidade. A Diretora Financeira é uma religiosa, e também é realizada a troca de conhecimentos e experiências com as demais unidades de negócio, já o Diretor Executivo, é um leigo (não religioso), com formação na área de gestão, que dá o suporte técnico necessário para as religiosas conduzirem as unidades de negócio, e, ainda a Coordenadora de Humanização e Espiritualidade, que também é religiosa, conduz a implantação das diretrizes da Rede, nas questões de humanização e espiritualidade.

O hospital possui um Diretor Técnico, formado em medicina, que é o responsável por conduzir o trabalho clinico dos médicos que trabalham no hospital. Para conduzir os trabalhos em nível tático e operacional, o hospital conta com um Gerente de Atendimento, que é responsável pela execução das estratégias da Rede no hospital. A instituição possui alvará sanitário de hospital geral válido, o que demostra atender na plenitude as normas da Vigilância Sanitária, Ministério da Saúde e demais legislações aplicáveis.

Para executar as atividades operacionais, orientados pelo Gerente de Atendimento, a estrutura é composta por quatro coordenadores: Coordenação Serviços, Coordenação Apoio, Coordenação Enfermagem I e Coordenação Enfermagem II. A Coordenação de Serviços é responsável pela execução das atividades de consultórios de especialidades, diagnóstico por imagem, internação, recepção e central telefônica. A Coordenação Apoio, responde pelas atividades de higienização, processamento de roupas, suprimentos, farmácia, obras, segurança do trabalho, serviços terceirizados e manutenção. As Coordenações de Enfermagem I e II são 
responsáveis pelas unidades de internação, centro cirúrgico, emergência, agência transfusional, serviço social, nutrição e demais serviços ligados a atividade fim do hospital.

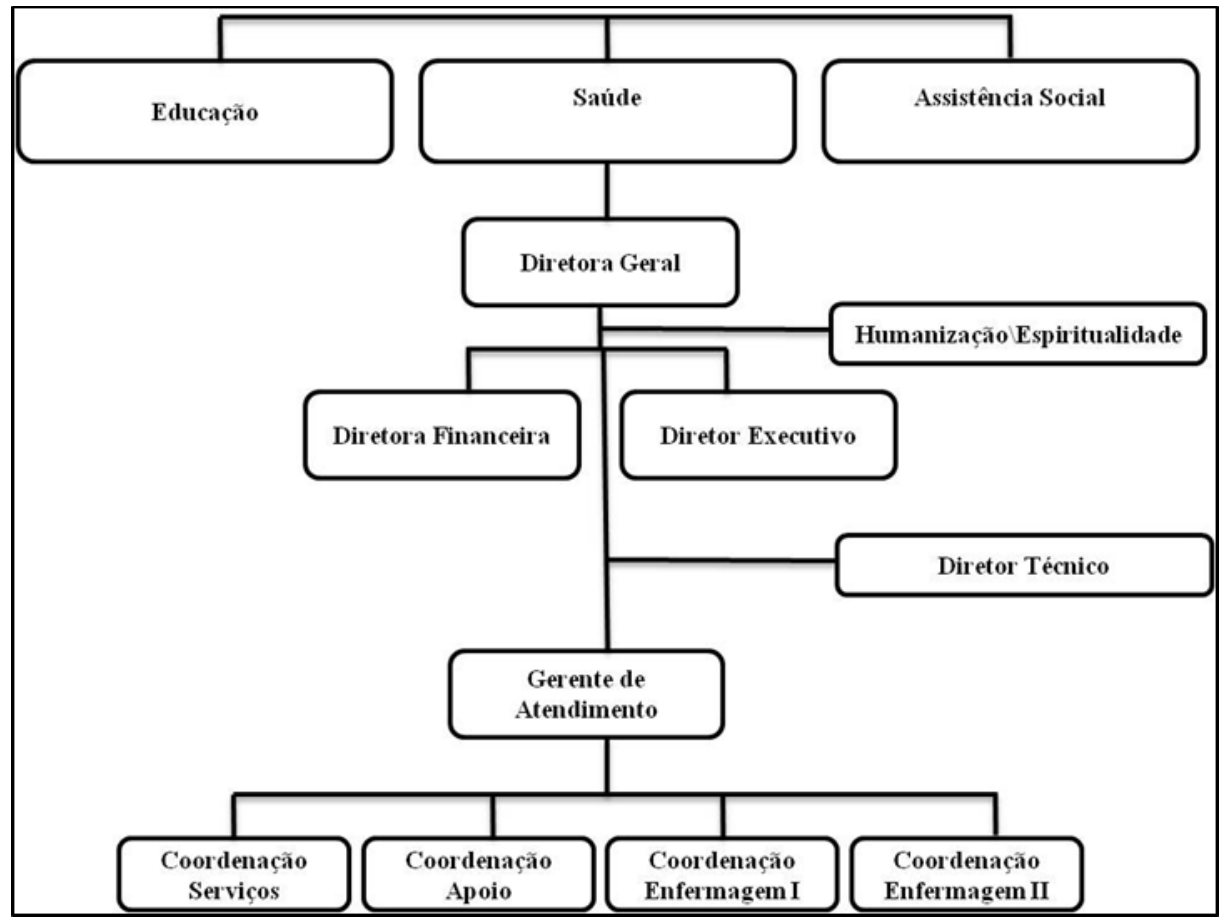

Figura 4: Organograma instância empreendimento - hospital

\section{CONSIDERAÇÕES FINAIS}

A forma de organização da Rede em Instância Canônica, Instância Institucional e Instância Empreendimento é uma configuração singular, que destoa das formas tradicionais de governança. Observou-se no estudo, a forte presença de religiosas na gestão da Rede e dos empreendimentos, e uma tendência de profissionais não religiosos em cargos estratégicos.

A governança corporativa da Rede segue as diretrizes do manual de boas práticas de governança corporativa (IBGC, 2009), o que demonstra que o sucesso alcançado por organizações de capital aberto, fez com que outras organizações buscassem utilizar as boas práticas de governança corporativa.

Tratando-se de uma Rede que atua em segmentos variados, com unidades de negócios distintos, percebe-se a importância da utilização das boas práticas de governança corporativa, com o objetivo de contribuir para a longevidade da organização.

No hospital objeto de estudo, observou-se a existência de um organograma enxuto, com as atividades estruturadas de acordo com a forma de gestão da unidade de negócio, onde, a governança corporativa está presente apenas em nível de Rede, ficando a unidade hospitalar, a operacionalização do negócio de acordo com as diretrizes institucionais. Entretanto, o hospital apresenta nível satisfatório de eficiência de gestão comparado aos demais hospitais da Rede, no qual trabalha a mais de uma década com o Modelo de Excelência de Gestão da Fundação Nacional 
da Qualidade - FNQ, que compreende as seguintes dimensões: liderança, estratégias e planos, clientes, sociedade, informações e conhecimento, pessoas, processos e resultados (FNQ, 2011).

Para estudos futuros sugere-se a análise dos demais hospitais da rede, afim de verificar o alinhamento organizacional existente e os impactos da governança corporativa adotada pela instituição.

\section{REFERÊNCIAS}

Andrade, A. \& Rosseti, J. P. (2004). Governança corporativa: fundamentos, desenvolvimento e tendências. São Paulo: Atlas.

Borba, G. S. de. \& Neto, F. J. K. (2008). Gestão hospitalar: identificação das práticas de aprendizagem existentes em hospitais. Revista Saúde e Sociedade. 17(1), 44-60.

Cerdaa, A. C de La. (2000). Tender Offers, Takeovers and Corporate Governance. The Latin America Corporate Governance Roundtable, São Paulo.

Daft, R. (1999). Administração. (4a ed.). Rio de Janeiro: Livros Técnicos e Científicos.

Fontes, J. R.,Ventura, E. C. \& Marucci, J. C. (2007). Cooperativa e o papel do conselho de administração em cooperativas de crédito no Brasil. In: Anais, 31 Encontro Anual da Anpad, Rio de Janeiro.

Freeman, R. (1984). Strategic management: a stakeholder approach. Massachusetts: Pitman.

FUNDAÇÃO NACIONAL DA QUALIDADE (FNQ). (2011). Critérios rumo a excelência. São Paulo: Fundação Nacional da Qualidade.

Gil, A. C. (2002). Como elaborar projetos de pesquisa. (4a ed.). São Paulo: Atlas.

Gonçalves, E. L. (1983). O hospital e a visão administrativa contemporânea. São Paulo: Pioneira.

Instituto Brasileiro de Governança Corporativa (2009). Código das melhores práticas de governança corporativa. São Paulo: IBGC.

. (2013). Código das melhores práticas de governança corporativa. São Paulo: IBGC.

Jensen, M. C., \& Meckling, W. H. (1976). Theory of the firm: Managerial behavior, agency costs and ownership structure. Journal of financial economics, 3(4), 305-360.

Kaplan, R. S. \& Norton, D. P. (2000). Organização orientada para a estratégia: como as empresas que adotam o balanced scorecard prosperam no novo ambiente de negócios. (4a ed.). Rio de Janeiro: Campus.

Loodi, J. B. (2000). Governança Corporativa: o governo da empresa e o conselho de administração. (10a ed.). Rio de Janeiro: Elsevier.

Ministério da Saúde. (2001). Assistência à Saúde no SUS. Brasília: Ministério da Saúde.

Mirshawka, V. (1994). Hospital fui bem atendido: a hora e a vez do Brasil. São Paulo: Makron Books.

Paula, M. G. M. A. (2000). Auditoria interna: Embasamento conceitual e suporte tecnológico. Revista contabilidade, gestão e governança, Brasília, 3(1), 79-110.

Porciuncula, J., Sausen, J. O. (2009). Análise do Processo de Mudança Estratégica em uma Organização Hospitalar: o caso do Hospital de Caridade de ljuí/RS. In: Anais, 33 Encontro Anual da Anpad, São Paulo.

Rezende, A. J., Facure, C. E. F. \& Dalmacio, F. Z. (2009). Práticas de Governança Corporativa em Organizações Sem Fins Lucrativos. In: Anais, 9 Congresso USP Controladoria e Contabilidade, São Paulo.

Santos, L. R. dos. (2004). A governança empresarial e a emergência de um novo modelo de 
controladoria. (Dissertação de Mestrado). Universidade de São Paulo, Programa de PósGraduação da Faculdade de Economia, Administração e Contabilidade, Universidade de São Paulo, São Paulo.

Vergara, S. C. (2009). Projetos e relatórios de pesquisa em administração. (10a ed.). São Paulo: Atlas.

Vilela, R. H. P., Ferraz, S. B., \& Ferraz, S. F. S. (2015). Modelo diagnóstico de Governança Corporativa em cooperativas de saúde. Revista de Administração FACES Journal, 14(1), 28-48. Yin, R. K. (2001). Estudo de caso: planejamento e métodos. (4a ed.). Porto Alegre: Bookman.

\section{Roteiro de entrevista}

1) Descreva a Instituição, suas áreas de atuação e a forma de trabalho em Rede.

2) A instituição possui Planejamento Estratégico?

3) É participante de programas de qualidade (PGQP, ISO, BPF, ACREDITAÇÃO)?

4) A instituição adota boas práticas de Governança Corporativa?

5) De que forma está organizada a gestão da Rede e do Hospital objeto do estudo?

6) Descreva os organogramas institucionais existentes.

7) Como a instituição trabalha os princípios básicos da governança corporativa (transparência, equidade, prestação de contas e responsabilidade corporativa)?

8) Descreva o Conselho Fiscal e o Conselho de Administração.

9) Como a auditoria interna e externa atuam na instituição?

10) O Hospital objeto do estudo está de acordo com as normas e legislações vigentes (ANVISA e Ministério da Saúde)?

11) Como você classifica a eficiência operacional do hospital pesquisado? 